\title{
Comprehensive Study of a Handheld Raman Spectrometer for the Analysis of Counterfeits of Solid-Dosage Form Medicines
}

\author{
Klara Dégardin, Aurélie Guillemain, and Yves Roggo \\ F. Hoffmann-La Roche Ltd., Bldg 250 Room 3.504.01, Wurmisweg, 4303 Kaiseraugst, Switzerland \\ Correspondence should be addressed to Klara Dégardin; klara.degardin@roche.com
}

Received 13 November 2016; Revised 25 January 2017; Accepted 15 February 2017; Published 5 March 2017

Academic Editor: Christoph Krafft

Copyright @ 2017 Klara Dégardin et al. This is an open access article distributed under the Creative Commons Attribution License, which permits unrestricted use, distribution, and reproduction in any medium, provided the original work is properly cited.

\begin{abstract}
The fight against medicine counterfeiting is a current focus of the pharmaceutical world. Reliable analytical tools are needed to pursue the counterfeiters. Handheld devices present the advantage of providing quick results, with analyses possibly performed on the field. A large number of solid-dosage form medicines have been analyzed with a handheld Raman spectrometer. 33 out of 39 product families could be successfully analysed. The methods were validated with $100 \%$ of correct identification. Each product was additionally tested by the methods of the other products and successfully rejected. A second validation was performed using counterfeits, placebos, and generics. All the counterfeits were rejected, with $p$ values close to zero. Some generics presented a similar formulation to the brand products and were then identified as such. One placebo was positively identified, showing that low dosage products are difficult to analyze with Raman. Robustness tests were carried out, showing, for instance, that the operator has no influence on the results and that the analyses might be performed through transparent packaging. The discovery mode was also investigated, which proposes the chemical composition of the samples. The results demonstrated that the Raman handheld device is a reliable tool for the field analysis of counterfeits.
\end{abstract}

\section{Introduction}

The pharmaceutical world is increasingly concerned with the counterfeiting of medicines. All types of medicines are targeted, as well as all regions of the globe. The quality of the counterfeits reaching the patients is very variable. In all cases, these products are dangerous for the patients, since they are not respecting the required hygiene for their good manufacturing [1-4]. Quick tools are consequently required for the analysis of suspect products, in order to speed up the investigations and increase the chances to pursue the criminals. Several analytical tools have proved efficient for the reliable and fast analysis of counterfeit medicines. Among them, spectroscopy is one of the most widely used, since it is mostly nondestructive and environment-friendly and requires no sampling [5]. Raman [6-12], near-infrared (NIR) [13-20], and midinfrared (MIR) [21-23] spectroscopy have been especially on the focus for counterfeit analysis.

Technological progress has enabled the development of handheld and portable spectrometers. The aim of these miniaturized devices is to be able to perform measurements on the field rather than having to send all the samples to the lab. Therefore, time can be spared for the analysis by performing a first screening of the samples. Handheld spectrometers are for instance more and more used for the field analysis of pharmaceuticals, agriculture, drugs, explosives, and mineral samples [24-33]. Handheld Raman, NIR, and MIR spectrometers have been especially studied and compared in the context of the analysis of counterfeit medicines [34-38]. Several handheld Raman devices have been evaluated in the literature. A dual-laser handheld Raman was evaluated by Assi et al. for the identification of three medicines with chemometrics [39], and another handheld Raman spectrometer for the authentication of 9 products and 22 test products using principal component analysis (PCA) [34]. Counterfeit medicines of three products were analysed by Luczak and Kalyanaraman [40]. Bate and Hess compared the results obtained with a handheld Raman instrument and the Minilab for the analysis of several antimalarial medicines [41] and for the authentication of antimalarial, 
antibiotic, and antimycobacterial medicines [42]. A handheld Raman spectrometer was tested on 15 pharmaceutical products by Bugay and Brush [43], and its specificity was evaluated by Hajjou et al. regarding the active pharmaceutical ingredient (API) content of six medicines [44]. Kalyanaraman et al. also presented the general use of such a device for counterfeit detection [45]. Ricci et al. compared the performance of a handheld Raman instrument with a benchtop device and desorption electrospray ionization (DESI) MS for the detection of counterfeits of antimalarials [46]. The use of a handheld Raman device on the field in Nigeria was finally presented by Spink et al. [47].

In this paper, a handheld Raman spectrometer was evaluated for the detection of counterfeits of a high number of pharmaceutical medicines, consisting in tablets, capsules, and powders. Robust methods were developed using a large database of products. In total, there are several batches of 33 product families, and among them, 62 formulations were measured, including the different manufacturing sites of the products. A detailed calibration and validation strategy was proposed, as well as some robustness tests, an evaluation of the discovery mode results for the composition of the confirmed counterfeits and a comparison with a lab instrument.

\section{Material and Methods}

2.1. Instrument Characteristics and Settings. A handheld Raman spectrometer was used to collect the spectra and perform the calibration. The device is a direct dispersive Raman using a $785 \mathrm{~nm}$ laser excitation wavelength. Its spectral resolution varies between 8 and $10.5 \mathrm{~cm}^{-1}$ in average, and the Raman shift range is 250 to $2875 \mathrm{~cm}^{-1}$. The integration time, in automatic mode, is of $12 \mathrm{~ms}$ minimum.

The tablet sample holder was used for the measurement of the tablets and capsules. Some of the samples had to be measured directly against the cone of the Raman since they were too large for the holder. While the tablets and the capsules were not measured in their packaging, the powders were analysed through their original glass vial.

2.2. Statistical Method. The statistical method used for the identification of the products was the one provided by the manufacturer. The calibration consisted in taking spectra of the genuine products. The device then computed automatically a "signature" of the product with each spectrum recorded. Several signatures of the same product were then gathered into a method. The signatures are based on a multivariate test of equivalence. This test is used to compare a newly acquired Raman spectrum and the reference spectra registered in the database. If the probabilistic value ( $p$ value) of the new spectrum is above or equal to 0.05 , meaning the spectrum presents a match within the preset 95 percent confidence limit, the measurement is considered consistent with the reference spectra and the device reports a "pass" result. If the $p$ value is inferior to 0.05 , the device reports a "fail" result. In the present method, while the validation with the genuine products should provide "pass" results, the counterfeits, generics, and placebos should provide a "fail" result.
The multivariate test of equivalence is computed using all the channels across the detector array region and can be considered a multivariate version of a statistical $t$-test. The uncertainty is directly modeled by the instrument software, and thus, no modeling has to be performed by the user.

2.3. Calibration and Validation Strategy. The calibration of the methods consisted in taking several spectra of a product, which were automatically converted in signatures, and gathering them into a single method. One method per product was ideally created. For products presenting different formulations between the dosages (different excipients), two or more methods were created per product.

The validation was performed with an independent set of spectra. The samples were tested on the methods in order to check if they were correctly recognized. All tested samples had to deliver a "pass" result with the appropriate method.

Additionally, the products were tested on all the other methods to check that no mismatch could occur for these products.

A second validation was then performed using counterfeits, placebos, and generics in order to test the ability of the handheld Raman spectrometer to detect counterfeits. The generics and the placebos were tested in order to mimic the "best case counterfeits." All these samples had to be rejected (present a "fail" result) by the instrument.

\subsection{Samples}

2.4.1. Genuine Samples. At least 5 batches per product were measured with the split of 3 batches for the calibration set and 2 batches for the validation set for each of the 62 studied formulations of the 33 product families. For the products manufactured in several sites, more than 5 batches were measured in order to include more variability. One sample per batch and three spectra per sample were measured. The samples were slightly moved (for the capsules and powders) or flipped (for the tablets) between each measurement. 543 signatures were acquired for the calibration, while the validation was performed with 392 spectra.

2.4.2. Placebos, Generics, and Counterfeits. 44 counterfeit samples (from eight different seizures) were tested, which had already been confirmed as counterfeits by previous analyses. In order to enlarge the number of samples, 3 placebos and 14 generics, from 5 different batches, were also tested against the methods. On the whole, 61 spectra were acquired for the second validation samples.

2.5. Robustness Tests. Once the methods were calibrated, validated, and tested against the counterfeits, placebos, and generics, 4 additional tests were performed in order to check the robustness of the methods.

The first robustness test (R1) consisted in measuring the same sample 20 times at the same position in order to see if the laser degraded the sample. Two samples (one tablet and one capsule) were tested.

In the second robustness test (R2), two samples (one tablet and one capsule) were measured 10 times at different positions in the sample holder. The objective was to evaluate 


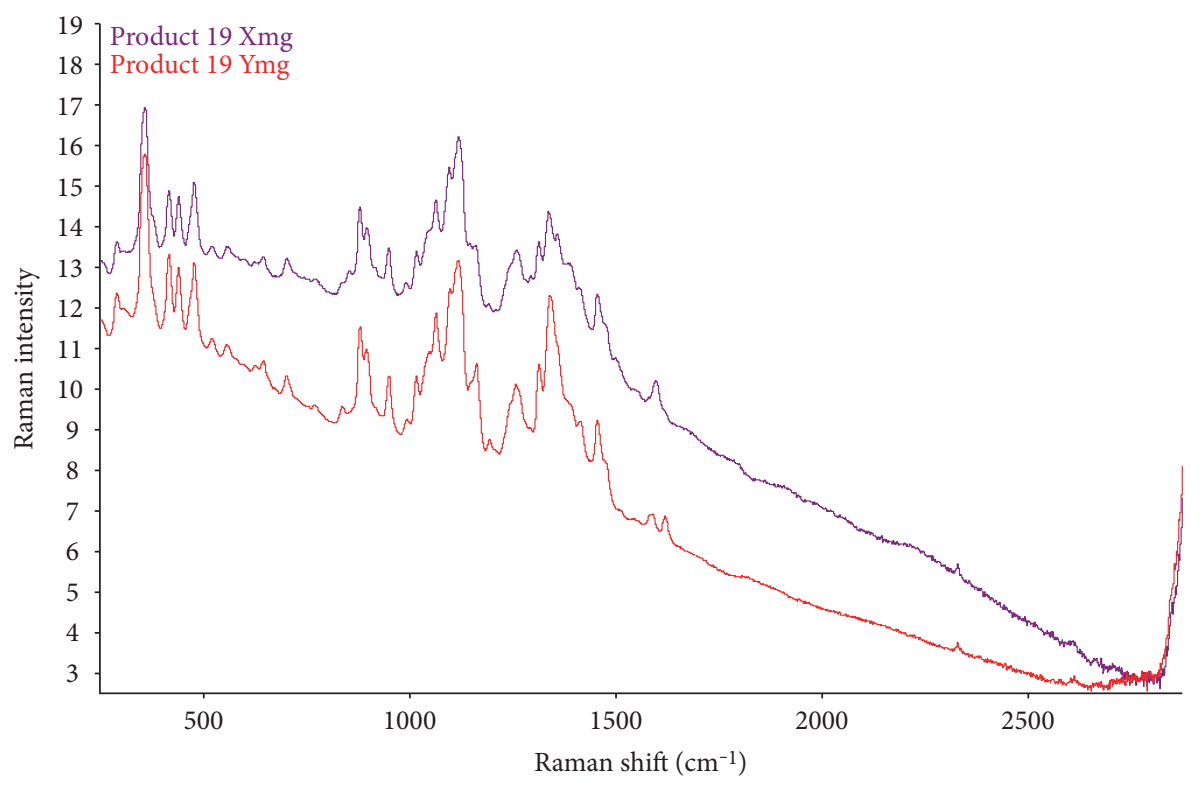

Figure 1: Raman spectra of two dosages of the same product family (product 19). Due to differences in the formulation, the product presents heterogeneous spectra.

if the position of the measurement had an influence on the result.

The influence of the sampling was evaluated in the third robustness test (R3). Three samples (one tablet and two capsules) were measured either through a glass vial, through a blister (transparent or white), or directly against the cone of the instrument.

Finally, the fourth robustness test (R4) consisted in measuring two samples (one tablet and one capsule) three times by two operators with the aim of testing if the operators had an influence on the measurement.

\section{Results and Interpretation}

3.1. Spectrum Interpretation. The spectra obtained by the device were first evaluated. Several challenges to the creation of the calibration could be pointed out.

First of all, it can be observed that some product families present heterogeneous spectra. Two or more dosages of the same product can indeed generate different spectra, when a different formulation-it means a different excipient profile-was used (see Figure 1). Additionally, in rare cases, the formulation can differ for the same product and the same dosage depending on the manufacturing site of the product (see Figure 2). It is thus important to include all the dosages and if possible all the manufacturing sites of a product into the methods. Different methods might then have to be created for one product if the spectra of the product family differ. Products 19 and 23 are indeed concerned by both the heterogeneity within the product family and the different formulations depending on the manufacturing site. Depending on the dosage or the manufacturing site, these products underwent changes in the composition of the sugar excipients, mainly going from lactose to starch. Since these excipients have a big influence on the spectral pattern of these low-dosage products $-0.3 \%, 0.6 \%$, and $1 \%$ API for product 19 and $1.3 \%$ and $6 \%$ API for product 23 -it might be difficult to perform the identification, unless separate methods are created per formulation.

Another challenge to the calibration is that similar excipient profiles can be found between different product families. The resulting spectra will then be similar, like the ones presented in Figure 3, and thus, the products will be hard to differentiate. This is the case for products 18 and 23, which contain the same excipients and have low dosage of API-2\% for product 18 and $50 \%$ and $83 \%$ for product 23. However, small spectral differences can be observed between products 18 and 23 in the range of 1500 and $1700 \mathrm{~cm}^{-1}$ and are due to API bands of product 18. The two other products concerned by the similarity of excipient patterns are products 31 and 32, which with their high content of API-83\% and 50\%-should however be distinguishable.

Some generics present formulations that are almost identical to the ones of the brand products. This will result in similar spectra that are not possible to distinguish from the brand product, like in the example in Figure 4. In these cases, a "pass" result can be expected.

Low-dosage products are difficult to analyse with Raman spectroscopy since the API will be hardly observed in the spectrum of the medicine. The limit of detection of API in Raman spectra is quite difficult to define, especially because it depends on the excipient pattern of the medicine. In the studied products, excipient patterns made of sugar, like starch, cellulose, or glucose, are predominant in the spectra and might mask the API bands. In a previous study, a limit of detection of $0.6 \%$ was encountered, while the authors indicated that the limit of detection was usually located around 1 or $2 \%$ of API [48]. For this reason, the placebos of 


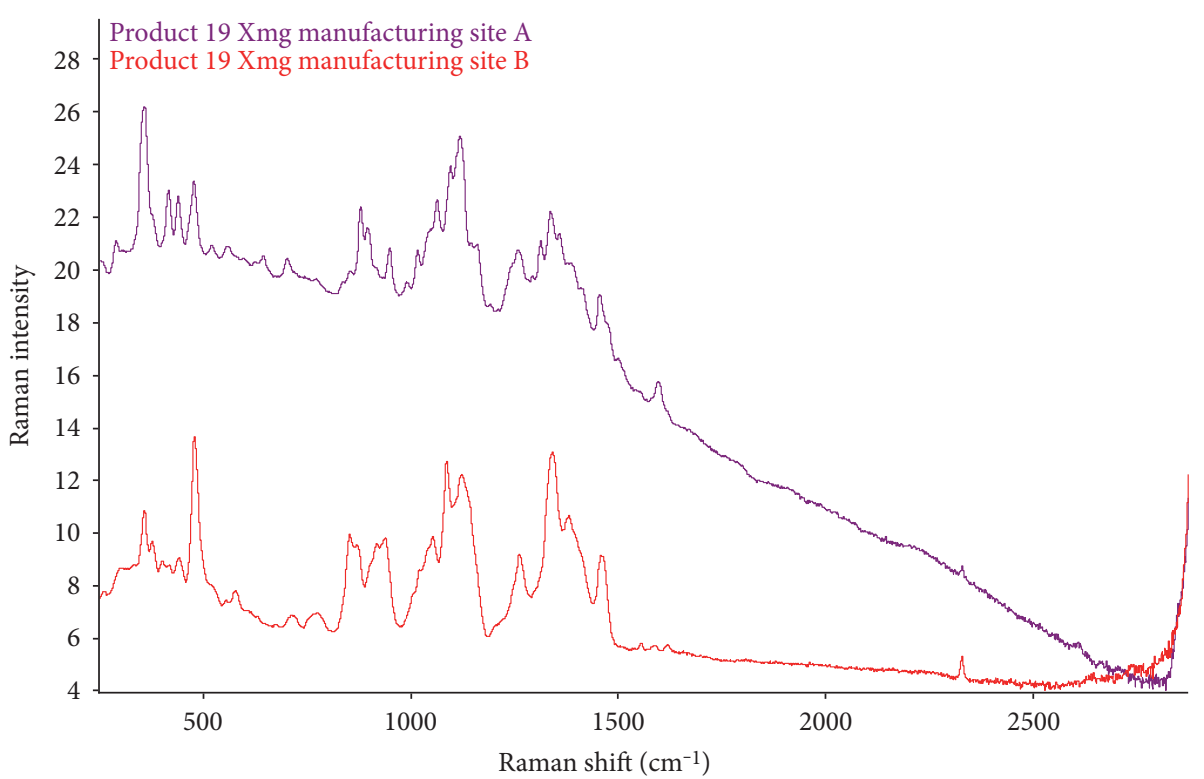

Figure 2: Raman spectra of two samples produced at different manufacturing sites and possessing the same dosage (product 19 Xmg). Due to differences in the chosen formulation, the product presents heterogeneous spectra.

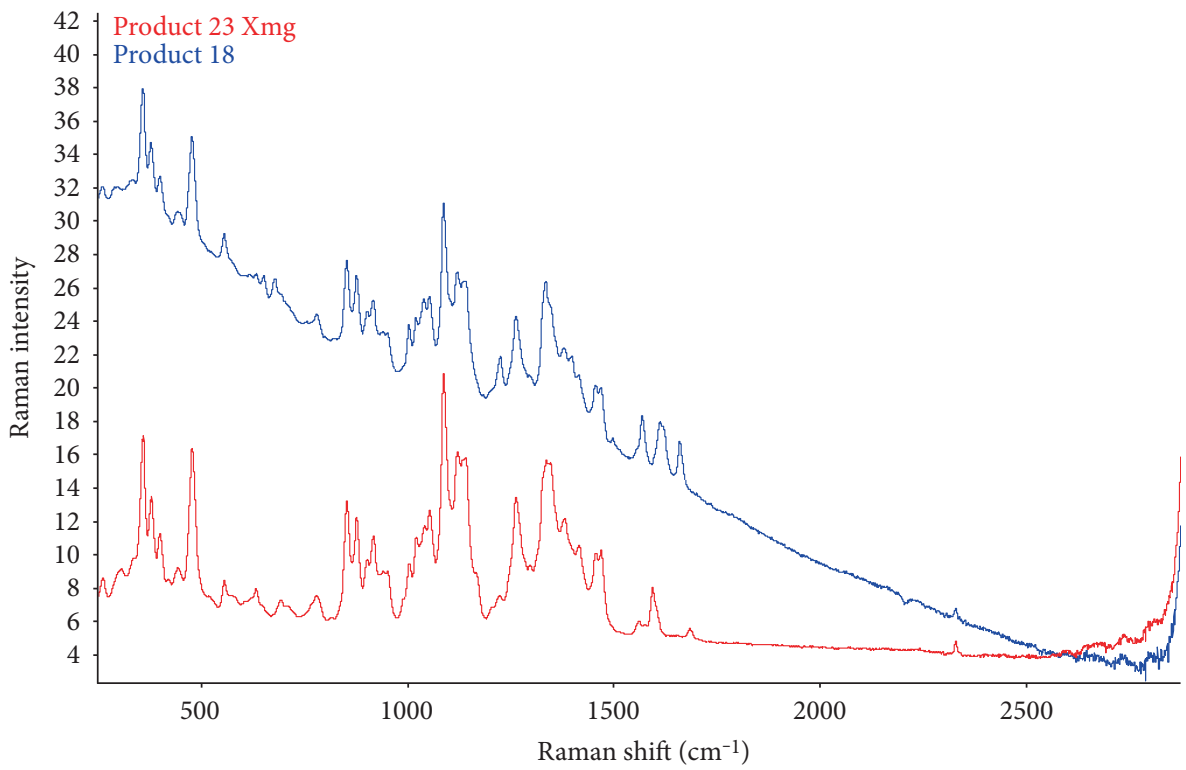

Figure 3: Raman spectra of two different products (product 18 and product $23 \mathrm{Xmg}$ ). The products present similar excipients profiles and thus close Raman spectra.

low-dosage products might provide spectra that are very similar to the genuine products. This was confirmed for product 26 which, with an API content of $0.6 \%$ and an excipient pattern dominated by starch and lactose, has identical spectra between the genuine product and its placebo.

The quality of the spectra might also have an influence on the calibration. The measured spectra present a wide range, from 250 to $2875 \mathrm{~cm}^{-1}$. The end of the range, approximately from 1800 to $2875 \mathrm{~cm}^{-1}$, is often noisy and not necessarily useful since it does not bring additional information about the product. Last but not least, a few samples, like product
32, underwent fluorescence (Figure 5). This phenomenon was observed when special excipients were used in the formulation of either the tablet or the shell of the capsules. In this study, in which a laser wavelength of $765 \mathrm{~nm}$ was used, indigo carmine (for product 32), microcrystalline cellulose, hydroxypropyl methylcellulose, and croscarmellose were found responsible for the fluorescence phenomenon. While the fluorescence made the identification harder, most bands of the API and the excipients could still be observed, like in Figure 5. When measuring other products, not presented in this paper, the fluorescence was however so strong that no signature could even be taken and no method created. 


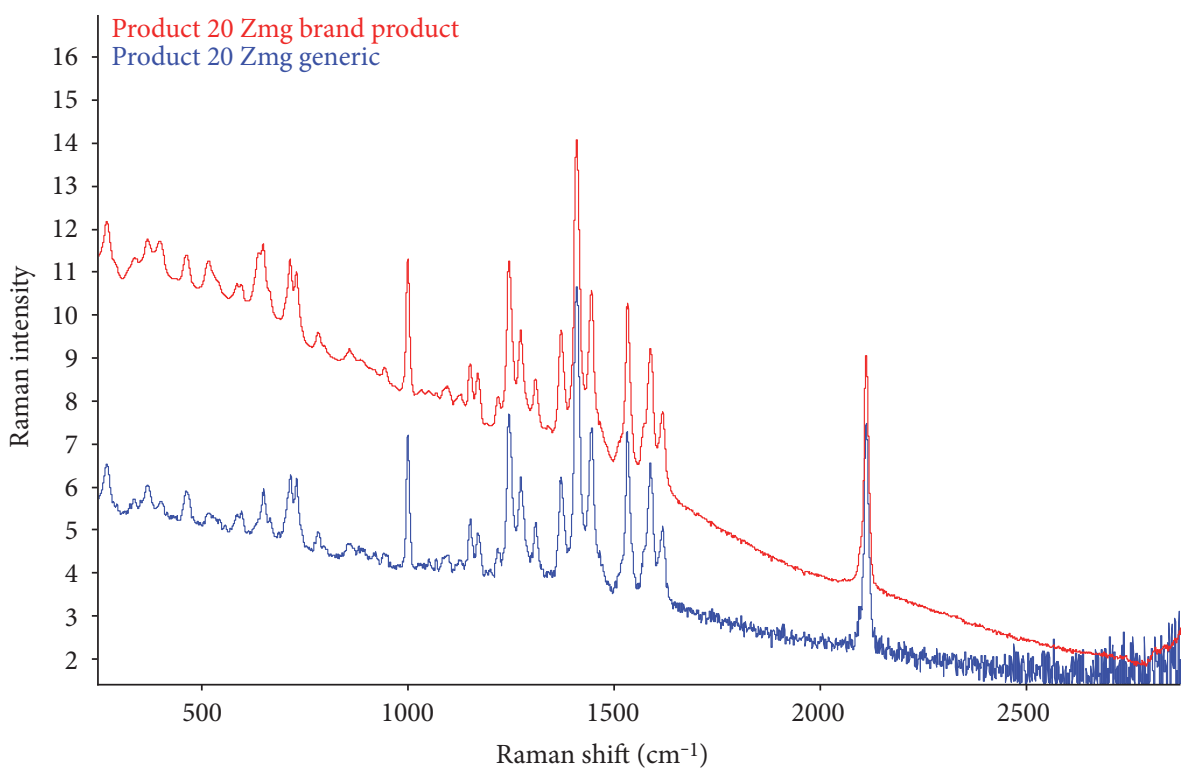

Figure 4: Raman spectra of a brand product and one of its generic (product $20 \mathrm{Zmg}$ ). Both samples present a similar formulation and the same dosage, and thus similar Raman spectra.

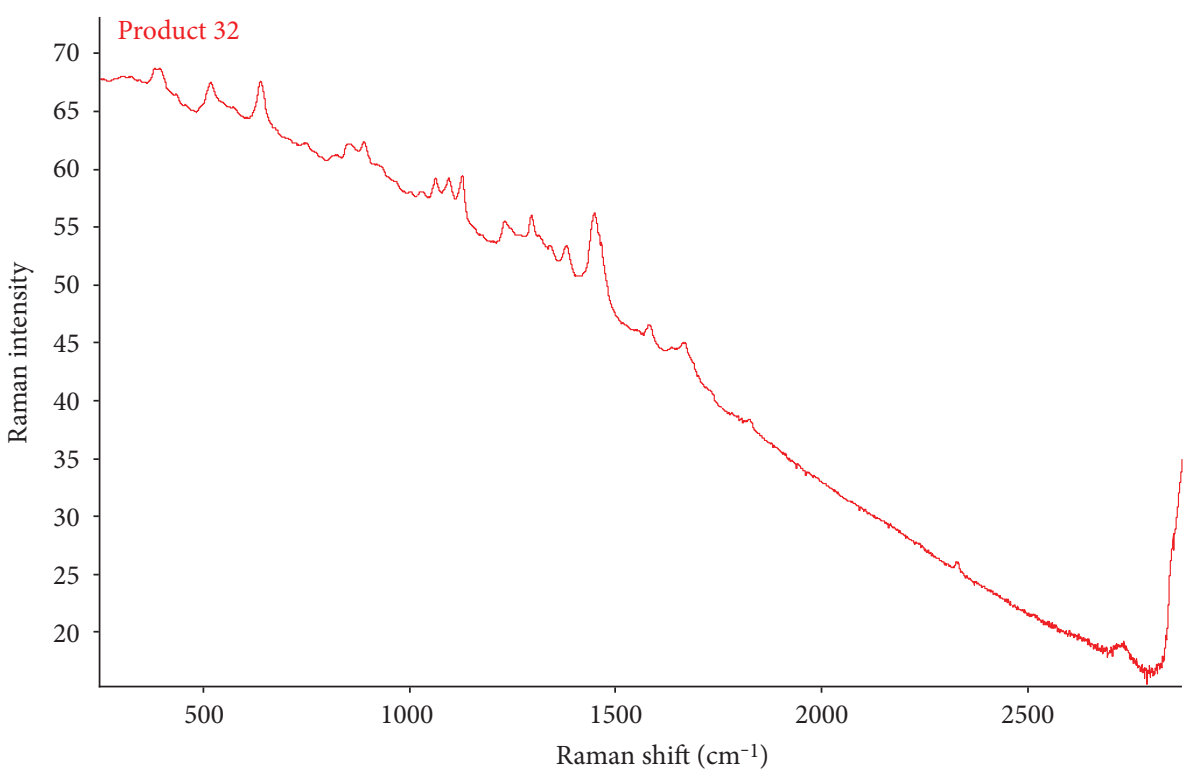

FIGURE 5: Raman spectrum of product 32. While a strong fluorescence phenomenon can be observed, the characteristic bands of the product are still visible, enabling a correct identification.

\subsection{Identification Results}

3.2.1. Calibration and Validation Results. There are 33 product families, and among them, 62 formulations could be successfully measured and integrated in the database of the instrument. In total, 31 methods have been created for tablets, 6 for capsules, and one for powders. Most methods gather spectra of several dosages per product. For the product families that presented heterogeneous formulations, several methods have been created.

$100 \%$ of the spectra from the validation set has been correctly identified according to the $\mathrm{pVal}$ limit for positive identification (superior to 0.05). According to the manufacturer, a pVal lower than 0.1 is considered too low for a robust method. For all the developed methods, the minimum pVal was higher than 0.1 (see Table 1).

Additionally, no confusion could be observed when testing the products on all the other methods than their dedicated method. $100 \%$ of all other products were rejected by the tested method. Table 1 presents the minimum $p$ values obtained for the validation samples of the corresponding method together with the maximum $p$ values of the closest other products. These values show that the methods were successfully validated and are very robust. 
TABLE 1: Validation results obtained with the genuine products. The number of signatures measured for each product has been added. The minimum $p$ values ( $\mathrm{pVal} \mathrm{min}$ ) obtained for the validation samples of the corresponding method are presented in the table together with the corresponding maximum $p$ values ( $\mathrm{pVal}$ max) of the closest other products. The device provides a positive identification for $p$ values superior or equal to 0.05 .

\begin{tabular}{|c|c|c|c|c|}
\hline \multirow[b]{2}{*}{ Sample type } & \multirow[b]{2}{*}{ Product (\%API) } & \multirow[b]{2}{*}{ Number of signatures } & \multicolumn{2}{|c|}{ Validation } \\
\hline & & & $\begin{array}{c}\mathrm{pVal} \text { min of } \\
\text { validation samples }\end{array}$ & $\begin{array}{l}\text { pVal max of closest } \\
\text { other products }\end{array}$ \\
\hline \multirow{29}{*}{ Tablets } & Product $1(71 \%)$ & 9 & 0.1404 & 0.0000 \\
\hline & Product $2(36 \%)$ & 9 & 0.5973 & 0.0105 \\
\hline & Product $2(72 \%)$ & 9 & 0.3576 & 0.0013 \\
\hline & Product $3(80 \%, 95 \%)$ & 18 & 0.5455 & 0.0000 \\
\hline & Product $4(67 \%, 75 \%)$ & 12 & 0.4137 & 0.0000 \\
\hline & Product $5(25 \%, 33 \%)$ & 18 & 0.3439 & 0.0171 \\
\hline & Product $6(61 \%)$ & 9 & 0.4847 & 0.0000 \\
\hline & Product 7 (57\%) & 9 & 0.4490 & 0.0007 \\
\hline & Product $7(56 \%)$ & 9 & 0.4106 & 0.0042 \\
\hline & Product $8(17 \%)$ & 9 & 0.4031 & 0.0083 \\
\hline & Product $9(3 \%, 6 \%, 12 \%, 30 \%)$ & 36 & 0.1292 & 0.0000 \\
\hline & Product $10(8 \%)$ & 9 & 0.5329 & 0.0044 \\
\hline & Product $10(4 \%)$ & 9 & 0.4481 & 0.0010 \\
\hline & Product $11(3 \%)$ & 9 & 0.6458 & 0.0129 \\
\hline & Product $12(75 \%)$ & 9 & 0.5785 & 0.0000 \\
\hline & Product $13(0.4 \%, 0.8 \%, 1 \%, 2 \%, 3 \%)$ & 54 & 0.4089 & 0.0145 \\
\hline & Product 14 (61\%) & 9 & 0.6009 & 0.0000 \\
\hline & Product $15(12 \%)$ & 9 & 0.4619 & 0.0167 \\
\hline & Product $16(51 \%)$ & 9 & 0.4299 & 0.0000 \\
\hline & Product $17(25 \%, 45 \%)$ & 27 & 0.4416 & 0.0000 \\
\hline & Product $18(2 \%)$ & 9 & 0.6275 & 0.0015 \\
\hline & Product $19(0.3 \%, 0.6 \%, 1 \%)$ & 24 & 0.1763 & 0.0009 \\
\hline & Product $20(24 \%, 32 \%)$ & 27 & 0.3453 & 0.0000 \\
\hline & Product $21(75 \%)$ & 6 & 0.5781 & 0.0000 \\
\hline & Product $22(70 \%)$ & 9 & 0.1562 & 0.0000 \\
\hline & Product $23(1 \%, 3 \%, 6 \%)$ & 36 & 0.4444 & 0.0348 \\
\hline & Product 24 (41\%) & 9 & 0.5872 & 0.0000 \\
\hline & Product $25(77 \%, 78 \%)$ & 18 & 0.5822 & 0.0000 \\
\hline & Product $26(0.8 \%)$ & 24 & 0.1807 & 0.0352 \\
\hline \multirow{6}{*}{ Capsules } & Product $27(83 \%)$ & 9 & 0.6223 & 0.0000 \\
\hline & Product 28 (49\%) & 9 & 0.5439 & 0.0000 \\
\hline & Product $29(76 \%)$ & 6 & 0.5920 & 0.0000 \\
\hline & Product $30(49 \%)$ & 9 & 0.1669 & 0.0000 \\
\hline & Product $31(83 \%)$ & 18 & 0.1218 & 0.0000 \\
\hline & Product $32(50 \%)$ & 9 & 0.1165 & 0.0000 \\
\hline Powders & Product $33(81 \%)$ & 30 & 0.6139 & 0.0000 \\
\hline
\end{tabular}

A selectivity test, proposed by the device, was evaluated after the validation. This test consists in evaluating for each method the risks of getting mismatches. The option was tested for the products providing the lowest $p$ values during the validation. For product 26 for instance, the selectivity test suggested that the closest other products would deliver a $p$ value of 0.0026 . Tested physically during the validation, the product actually delivered a $p$ value of 0.0352 using the method of product 26 . While the selectivity test might be an option to see quickly if possible mismatches might occur, the results delivered are not real. The validation performed in this study is thus considered more completed than the selectivity test. Raman can thus not be considered a universal method for counterfeit detection.

For six other products not included in the 33 presented product families, no method could be created since the 
TABLE 2: Second validation results obtained with the challenging samples. The number of samples measured for each product has been added. The maximum $p$ values ( $\mathrm{pVal}$ ) obtained for each counterfeit are presented in the table together with the corresponding pass/fail result.

\begin{tabular}{|c|c|c|c|c|}
\hline Sample set & Counterfeited product & Number of samples & pVal max & Identification against the corresponding method \\
\hline \multirow{8}{*}{ Counterfeits } & Product 27 & 2 & 0.0000 & Fail \\
\hline & Product 6 & 6 & 0.0000 & Fail \\
\hline & Product 28 & 3 & 0.0000 & Fail \\
\hline & Product 26 & 1 & 0.0000 & Fail \\
\hline & Product 19 & 5 & 0.0001 & Fail \\
\hline & Product 23 & 10 & 0.0000 & Fail \\
\hline & Product 25 & 7 & 0.0000 & Fail \\
\hline & Product 32 & 10 & 0.0003 & Fail \\
\hline \multirow{3}{*}{ Placebos } & Product 4 & 1 & 0.0000 & Fail \\
\hline & Product 32 & 1 & 0.0040 & Fail \\
\hline & Product 26 & 1 & 0.5257 & Pass \\
\hline \multirow{7}{*}{ Generics } & Product 20 & 1 & 0.4937 & Pass \\
\hline & Product 25 batch 1 & 2 & 0.0224 & Fail \\
\hline & Product 25 batch 2 & 3 & 0.6326 & Pass \\
\hline & Product 32 batch 1 & 1 & 0.0042 & Fail \\
\hline & Product 32 batch 2 & 4 & 0.1548 & Pass \\
\hline & Product 5 & 2 & 0.0110 & Fail \\
\hline & Product 33 & 1 & 0.1295 & Pass \\
\hline
\end{tabular}

fluorescence prevented the measurement of the signatures. Among these six products, two were tablets, two were capsules, and two were lyophilized products. Since no signatures could be taken with these samples, the results are not displayed in this paper.

3.2.2. Second Validation with Counterfeits, Placebos, and Generics. All the tested counterfeits, consisting in 44 samples, failed for identification. The obtained $p$ values were very low-inferior to 0.0003 - which comforted the robustness of the methods for the detection of counterfeits. The details of the results of the second validation are presented in Table 2.

Nine of the tested generics have the same formulation as the genuine brand products, and their spectra are identical, as previously presented in Figure 4. These samples were consequently identified by the device as genuine. Since the objective of the methods is to reject, counterfeits and generics were only used to simulate them; these results are not considered critical. The other five generics were rejected by the methods. The $p$ values obtained are highly dependent on the tested generic.

Two of the three tested placebos were rejected by the methods. The third one, the placebo of product 26, was detected by the instrument as genuine with a maximum $p$ value of 0.5257 , which is very high. The method for product 26 , a low-dosage product, was then considered not specific enough and was then deleted from the database.

The results of the validation and the tests performed for the second validation are summarized in Table 3 .

3.3. Robustness Results. The results of the four robustness tests are presented in Table 4.
According to the first test, a capsule of product 31 and a tablet of product 20 were measured 20 times at the same position to check if the samples were damaged by the laser. The capsule and the tablet were correctly identified even after 20 measurements. Additionally, no important variation of the $p$ value range was observed, which confirms that the laser did not damage the samples. At this point, it should be noted that no soft-gel capsules should be measured with the Raman instrument since their shell is very sensitive to the heat of the laser.

A capsule of product 31 and a tablet of product 20 were each measured 10 times for the robustness test R2. They were moved between each measurement in order to check if the position of the sample had an influence on the results. The samples were correctly identified during each measurement, with little difference in the $p$ values. This means that the position of the samples has low influence on their identification. However, it is recommended to measure the capsules on the side where there is only one layer of gelatin. Also, care should be taken in order not to break the samples with the sample holder. For instance, if a tablet is broken and its coating removed due to the breaking, then a slightly different spectrum can be obtained, which might alter the results.

The robustness test $\mathrm{R} 3$ deals with the sampling that is available for the studied medicines. Three products were measured either directly with the sample holder, through transparent glass vials, or through blisters, depending on the available packaging. Two types of blister were evaluated: transparent (plastic) and white (plastic). The samples were all correctly authenticated when measured directly, through transparent glass vials and through transparent blisters. The products could not be correctly identified through white blister. It is consequently recommended to use the tablet 
TABLe 3: Overview of the results obtained for the validation and the tests of the second validation. $\left(^{*}\right)$ In these tests, "fail" is actually the expected answer, since these products should not be identified by the method.

\begin{tabular}{lcr}
\hline Step of the method development & Sample set & Results of the identification \\
\hline Validation & Validation with positive samples & $100 \%$ pass \\
& (e.g., product 1 tested on the method of product 1) & Validation against all other products \\
& (e.g., product 1 tested on the method of product 2) & $100 \%$ fail $^{*}$ \\
Second validation & Counterfeits & $100 \%$ fail $^{*}$ \\
& Placebos & $67 \%$ fail $^{*}$ \\
& Generics & $35 \%$ fail $^{*}$ \\
\hline
\end{tabular}

TABLe 4: Results of the four robustness tests. The conditions of the test, like the sampling, have been added together with the number of spectra measured. The results consist in the $p$ value range and the pass/fail answers.

\begin{tabular}{|c|c|c|c|c|c|}
\hline Robustness test & Product & Conditions & $\begin{array}{c}\text { Number of } \\
\text { spectra }\end{array}$ & $\mathrm{pVal}$ results & $\begin{array}{c}\text { Identification against } \\
\text { the corresponding method }\end{array}$ \\
\hline \multirow{2}{*}{$\begin{array}{l}\text { R1: degradation } \\
\text { with the laser }\end{array}$} & Product 20 & No change in sample position & 20 & {$[0.5745-0.6669]$} & Pass \\
\hline & Product 31 & No change in sample position & 20 & {$[0.5616-0.7335]$} & Pass \\
\hline \multirow{2}{*}{$\begin{array}{l}\text { R2: influence of } \\
\text { the sample position }\end{array}$} & Product 20 & Sample position changed & 10 & {$[0.5523-0.6746]$} & Pass \\
\hline & Product 31 & Sample position changed & 10 & {$[0.3316-0.6481]$} & Pass \\
\hline \multirow{9}{*}{$\begin{array}{l}\text { R3: influence of } \\
\text { the sampling }\end{array}$} & \multirow{3}{*}{ Product 20} & Glass vial & 3 & {$[0.5386-0.5950]$} & Pass \\
\hline & & Transparent blister & 3 & {$[0.5891-0.6534]$} & Pass \\
\hline & & Direct & 3 & {$[0.5344-0.5746]$} & Pass \\
\hline & \multirow{3}{*}{ Product 32} & Glass vial & 3 & {$[0.1131-0.2471]$} & Pass \\
\hline & & Transparent blister & 3 & {$[0.0814-0.3385]$} & Pass \\
\hline & & Direct & 3 & {$[0.1628-0.4482]$} & Pass \\
\hline & \multirow{3}{*}{ Product 27} & White blister & 3 & {$[0.0175-0.0259]$} & Fail \\
\hline & & White blister & 3 & {$[0.0272-0.1164]$} & Fail \\
\hline & & White blister & 3 & {$[0.0017-0.0731]$} & Fail \\
\hline \multirow{4}{*}{$\begin{array}{l}\text { R4: influence of } \\
\text { the operator }\end{array}$} & \multirow{2}{*}{ Product 20} & Operator A & 3 & {$[0.6815-0.6871]$} & Pass \\
\hline & & Operator B & 3 & {$[0.6143-0.6526]$} & Pass \\
\hline & \multirow{2}{*}{ Product 31} & Operator A & 3 & [0.6159-0.6779] & Pass \\
\hline & & Operator B & 3 & {$[0.6599-0.7381]$} & Pass \\
\hline
\end{tabular}

holder to measure the samples. However, it is interesting to note that according to this test, a product measured on the field through transparent blister or in transparent glass vials might be correctly authenticated.

In order to evaluate the human influence (test R4), a tablet of product 20 and a capsule of product 31 have been measured three times by two different operators. The samples were all correctly identified, and the obtained $p$ values are very close between the operators. It seems that the operators have no influence on the identification, which is an important factor for the use on the field. It should be noted that both operators were properly trained before the robustness test.

3.4. Composition of the Counterfeits. As soon as a counterfeit has been confirmed, it is necessary to determine its chemical composition in order to estimate the impact on the patients' safety. In this frame, the discovery mode of the instrument has been evaluated with the studied counterfeits. This mode proposes, in case of a "fail" result, the chemical composition of the tested sample. This composition is suggested according to the database furnished by the supplier and integrated in the device. The database contains more than 8000 references of excipients and active substances and was completed by the studied products during the calibration.

Several samples per counterfeit seizures have been analysed with the device and interpreted with the discovery mode. Their chemical composition was previously determined by the lab instruments, a Raman, a near-infrared, and a nuclear magnetic resonance spectrometers.

For 14 samples, no match could be found with the instrument database. This can be explained by the fact that for these samples, the chemical composition was a mixture of at least three components, part of the database, but difficult to detect all with an automatic Raman database search.

The second point is that for 10 counterfeits, a different composition was proposed by the device between the different samples of the same seizure. Once again, it can be explained by the complex mixture of the counterfeits. Some components could be identified, while others not. For instance, for 
the counterfeits of product 19, made of melatonin, starch, and saccharose, melatonin is missing in the search of the device. While it is observable in the Raman spectra, the bands are too small to be detected by an automatic search.

In three cases (product 29 seizures number 2 and number 3 and product 33 ), the chemical composition proposed by the discovery mode was correct. The counterfeits are only made of one component, an API, easy to identify by Raman.

It can be concluded that some of the compounds of the counterfeits are common compared to the "right" composition determined by the lab instruments. While the discovery mode can help the analyst determine the chemical composition of the confirmed counterfeits, it cannot be reported as the right composition. It should be noted that in the discovery mode, the operator also has access to the overlay of the tested sample and the encountered matches of the database. The spectra can then be visually compared to evaluate if the proposed matches are correct or not. In this case, the operator should however be a Raman specialist.

3.5. Comparison with a Lab Instrument. In order to evaluate the quality of the data generated by the handheld Raman spectrometer, these were compared with the Raman spectra obtained with a benchtop instrument. The chosen instrument is a Raman spectrometer equipped with a probe generating a $6 \mathrm{~mm}$ diameter laser spot. The device possesses a laser of $785 \mathrm{~nm}$, providing a power of $270 \mathrm{~mW}$ on the samples, and a spectra range going from 150 to $1890 \mathrm{~cm}^{-1}$.

Figures 6(a) and 6(b) present examples of overlaid spectra generated by the handheld and the benchtop Raman spectrometers. Two types of spectra are represented for the handheld device: the ones generated while taking a signature and the others generated during simple measurements; it means routine analysis or method validation.

The spectra generated by both devices for the signatures are both of good quality and are almost identical. The ones generated by the handheld Raman spectrometer during simple measurements are much noisier. However, the main bands are easily observed and the spectra used for validation all provided $100 \%$ of correct identification.

It can also be noted that the range used by the handheld Raman spectrometer, longer than the one of the benchtop device, does not bring much more information and is usually the noisiest part of the spectrum. However, based on the validation results, this additional range $\left(1890-2900 \mathrm{~cm}^{-1}\right)$ does not seem to have a negative impact on the identification.

The results of the calibration obtained by both devices can be partly compared for the tablets while referring to a previous study performed with this lab instrument [48]. In both cases, $100 \%$ of the samples used for the calibration and for the validation have been correctly identified. Consequently, the results obtained by the handheld Raman spectrometer are in the present case as good as the ones obtained with the lab instrument.

\section{Discussion}

In this paper, methods have been presented for the authentication of almost all the solid products produced by the firm.
The database consists indeed in 33 product families, and among them are 62 product formulations. The calibration and validation could be successfully performed for all of these products. Moreover, the methods were validated against all the other products of the database, which were successfully rejected by the studied methods. Several challenges, raised during the spectra analysis, have been encountered during the development of the presented methods. The heterogeneity of the product families and the closeness of formulation between different families could be solved by the high number of signatures taken and their correct gathering in the methods. The importance of taking several spectra, especially of samples from different manufacturing sites, should be underlined. All the tested counterfeits were rejected by the methods, which confirms the dedicated use of the handheld Raman spectrometer for counterfeit detection. Some generics were recognized as genuine brand products, however, only when their formulation was really close. These results were not considered critical since the objective of the methods was to detect counterfeits, and not generic products. The tested placebos were rejected by the methods, apart from one sample, the placebo of product 26. Consequently, product 26 was deleted from the database after the second validation phase. This test suggests that for lowdosage products, an additional analytical technique should be used that would confirm the presence of the API. In these cases, a fingerprint of the whole tablet is nevertheless available by Raman, meaning that at least the right excipients are present in the tested product [48].

Six products, not included in the 33 presented products, could not be measured at all by the instrument since the fluorescence prevented the acquisition of the signatures. Fluorescence constitutes the main drawback of the Raman technology, which can be on other instruments diminished for instance by the use of a fluorescence correction option or the use of a different wavelength like $1084 \mathrm{~nm}$. In the present case, no solution can be found for the products presenting fluorescence. However, a large majority of the tested products could be successfully measured with the handheld Raman spectrometer. Furthermore, the results obtained with the handheld Raman spectrometer were compared to the ones generated by a lab instrument. It resulted that the handheld instrument delivered good results as the lab Raman spectrometer.

The robustness tests performed during the validation demonstrated that the laser did not damage the samples. Moreover, no influence could be observed of the sample position or the operator. However, it was pointed out that the operators had to be trained so that they would position the samples carefully. Also, the samples should not be damaged when placed on the device, for instance by removing involuntarily the coating, or measured through a thick layer of capsule shell. A trained operator could consequently perform the measurement on the field and be able to authenticate the samples without needing further knowledge in Raman spectroscopy. The fourth robustness test showed that a measurement through a white blister did not allow the identification of the capsule. Since the measured product (product 27) contains $83 \%$ of API, this confirms that 


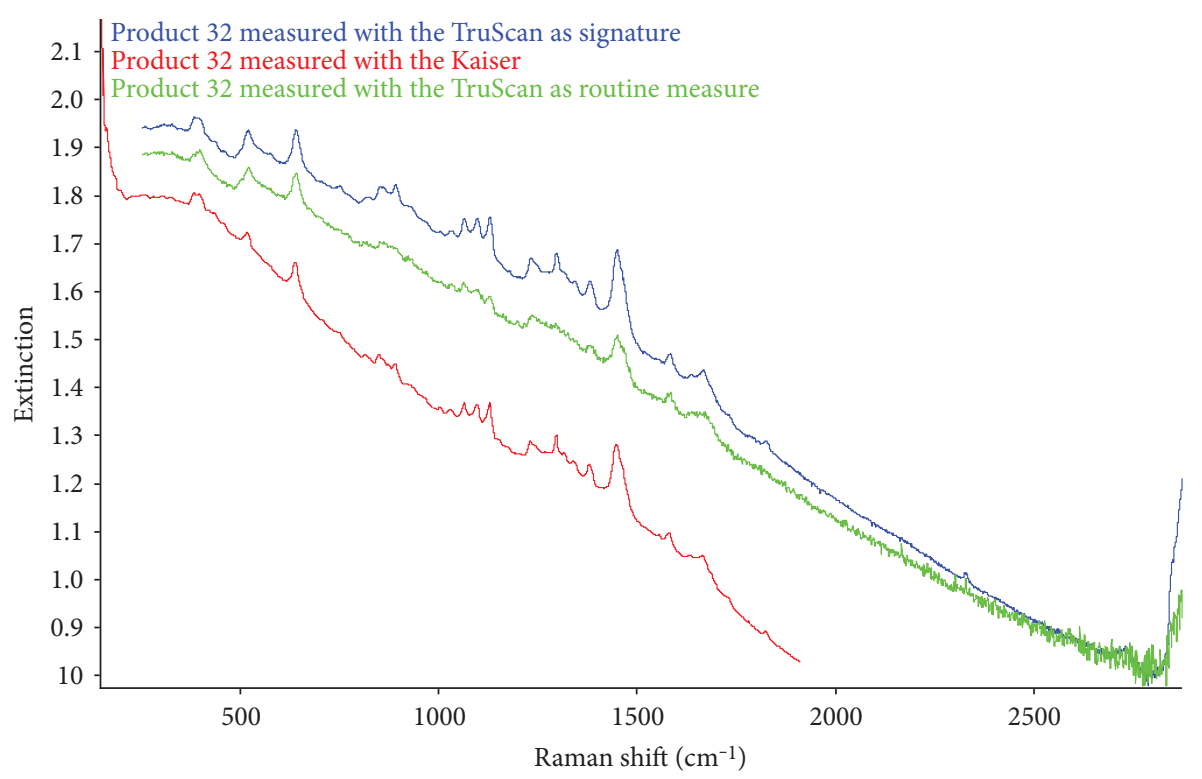

(a)

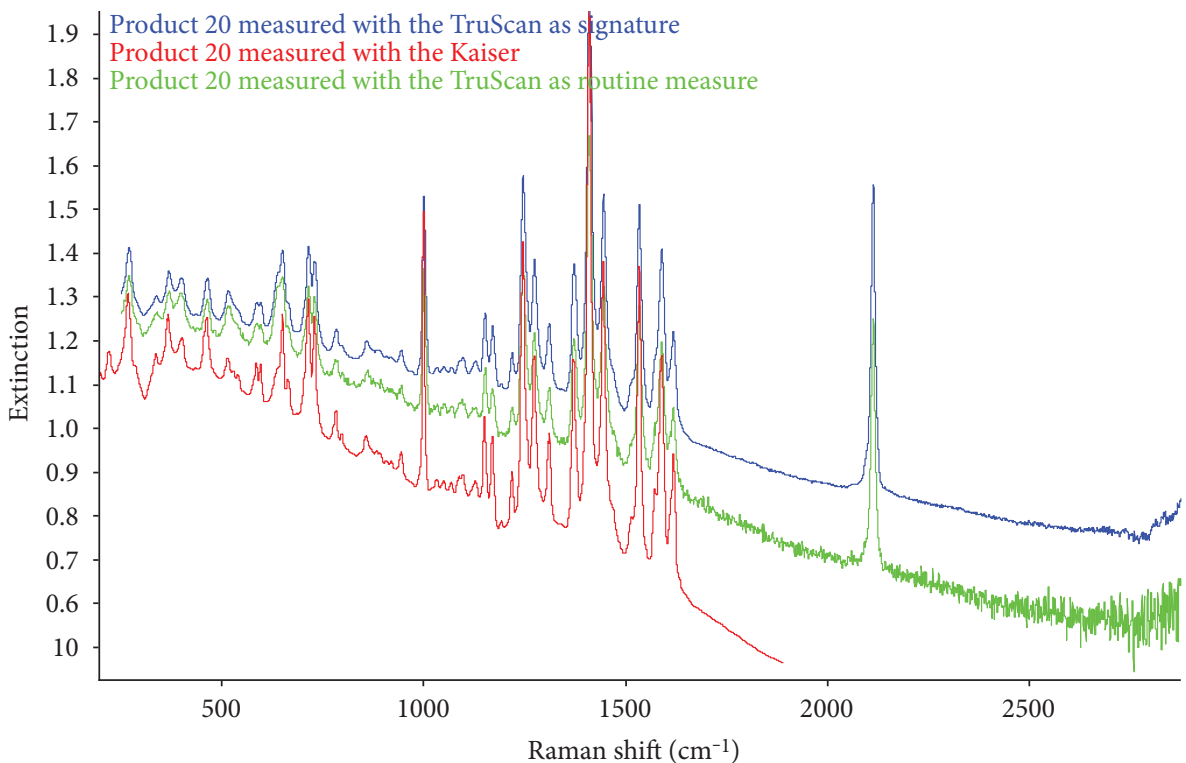

(b)

Figure 6: Overlay of Raman spectra obtained with the TruScan Thermo ${ }^{\circledR}$ (signature and routine measure) and the RXN1 Kaiser Optical Systems ${ }^{\circledR}$ devices for product 32 capsule (a) and product 20 tablet (b).

this can be attributed to the type of packaging. Furthermore, transparent packaging like glass vial or blister delivered the same results as in direct contact with the instrument in the sample holder. This fact could be of advantage during a measurement on the field, since a nondestructive measurement should always be privileged. While Raman spectroscopy is not destructive in itself, it can be considered destructive if tablets or capsules have to be removed from their packaging for the analysis.

Handheld Raman spectrometers are also interesting for counterfeit detection for the reason that a method can be developed on a master instrument and then easily transferred to several other ones for a local measurement on the field, for instance at airports, at the customs, or in warehouses. In this frame, the transfer of the presented methods to another instrument is quite easy. The transfer basically only consisted in the copying of files from the master device on the new device. Then, each method can be tested with an independent set of samples in order to check that the spectrometer has no influence on the measurement. At this point, the introduction of all possible manufacturing sites in the database is particularly important if the new instrument is going to be used for the testing in another region of the world. That way, much fewer false negatives should be expected. The use of the handheld devices on the field would help speed up the investigation, by reducing the time spent by sending the samples. It is however recommended to send the samples that failed the identification with the handheld Raman 
spectrometer to labs in order to confirm the counterfeits and perform the analysis of the whole chemical composition. Indeed, the test conducted in this study concerning the discovery mode of the instrument revealed that in most cases, and based on the previous analyses performed with diverse technologies, the proposed chemical composition was not correct. This mode is able to determine the composition when the counterfeits are only made of one component. For the analysis of mixtures, a manual spectrum interpretation and further analyses are required.

The main advantage of the studied instrument resides in how easy the method calibration is. Indeed, no further knowledge in Raman spectroscopy or chemometrics is required, although knowledge in method validation should be privileged. The proposed algorithm automatically calculates the $p$ values while taking signatures of the products. Nevertheless, this system might be considered a "black box" with no possible way of modifying the calibration of the method. The opportunity of choosing further chemometric tools would be welcome, which seems to be possible in the newest versions of the device. Indeed, the more products are introduced in the database, the more flexibility is needed to develop a robust calibration. Also, it would be of advantage to be able to change the sample exposure during the routine measurements. In fact, the quality of the spectra is worse during this phase than during the signature mode, which might generate less reliable results. The end of the range $\left(1890-2900 \mathrm{~cm}^{-1}\right)$ is additionally not of great interest for the studied products and represents the noisiest part of the spectrum. A compromise might be found between the time of measurement, partly dependent on the sample exposure, and the quality of the spectra. Finally, another possible improvement of the device would be the possibility of importing spectra from another device. Even if the calibration step is as fast as possible concerning the computation, taking signatures of a large database of products and validating all of them require many hours of measurements. The spectra should in this case be transformed with calibration transfer techniques and the methods carefully validated since they are spectrometer dependent, but a lot of time would be spared in the measurement phase.

\section{Conclusion}

Handheld spectrometers are more and more used for the onsite analysis of pharmaceuticals. In this paper, a handheld Raman spectrometer has been evaluated for the analysis of counterfeits of 33 product families of medicines under the form of tablets, capsules, and powders. Several challenges had to be dealt with during the calibration of the methods, like the heterogeneity of several product families or the closeness of formulation between different products. Nevertheless, the methods could be successfully created and fully validated. The tested counterfeits were rejected by the methods, thus confirming the specificity of the calibration for counterfeit detection. The methods were also proved to be robust in terms of degradation by the laser, sample positioning, and influence of the operators. The samples could be partly measured through the packaging, depending on their opacity.

Some limits could nevertheless be found concerning the instrumentation, like the positive identification of some generics and one placebo. The device is not adapted to the measurement of low-dosage medicines, for which a complementary method like infrared spectroscopy should be used. Moreover, the analysis of the chemical composition, suggested by the discovery mode of the device, does not provide correct results as soon as more than one component is included in the counterfeit. While the calibration is performed quite quickly, the chemometrics cannot be chosen and the method developer has to rely on the proposed algorithm. Finally, the spectra obtained during the routine measurements are quite noisy and might generate false negative results. Apart from these encountered limits, the handheld Raman spectrometer performed very well for the identification of the 33 product families of medicines and is uncontestably a reliable tool for the analysis of counterfeit medicines on the field. More and more handheld devices are being used in this context, which should be encouraged in order to speed up the investigations and provide better chances to pursue the criminals. While the handheld Raman spectrometer might be used as a first screening tool on the field, the counterfeits detected can be sent to a lab for confirmation and determination of the chemical composition for the evaluation of the patient's health risk.

\section{Conflicts of Interest}

The authors declare that there is no conflict of interest regarding the publication of this paper.

\section{References}

[1] C. del Castillo Rodriguez and M. J. Lozano Estevan, "Counterfeit medicine. A threat to health. Legal situation," Anales de la Real Academia Nacional de Farmacia, vol. 81, no. 4, pp. 329-333, 2015.

[2] K. Dégardin, Y. Roggo, and P. Margot, "Understanding and fighting the medicine counterfeit market," Journal of Pharmaceutical and Biomedical Analysis, vol. 87, pp. 167-175, 2014.

[3] J. Harris, P. Stevens, and J. Morris, Keeping It Real. Combating the Spread of Fake Drugs in Poor Countries, International Policy Network, 2009, April 2014, http://www.africanliberty. org/pdf/Keepingitreal.pdf.

[4] E. Medina, E. Bel, and J. M. Sune, "Counterfeit medicines in Peru: a retrospective review (1997-2014)," BMJ Open, vol. 6, no. 4, pp. 1-11, 2016.

[5] S. Garrigues and M. de la Guardia, "Non-invasive analysis of solid samples," Trends in Analytical Chemistry, vol. 43, pp. 161-173, 2013.

[6] F. Adar, E. Lee, A. Whitley, and M. Witkowski, Single-Point Analysis and Raman Mapping of Tablet Dosage Formulation as a Means for Detecting and Sourcing Counterfeit Pharmaceuticals, Pharmaceutical Online, 2007, March 2011, http:// www.pharmaceuticalonline.com/download.mvc/Single-PointAnalysis-And-Raman-Mapping-Of-Do-0001?user=20.

[7] M. Boiret, D. Rutledge, N. Gorretta, Y. M. Ginot, and J. M. Roger, "Utilisation de la Microscopie Raman et des Méthodes 
Chimiométriques pour la Détection de Comprimés Contrefaits," Spectra Analyse, vol. 298, pp. 74-80, 2014.

[8] K. Dégardin, Y. Roggo, F. Been, and P. Margot, "Detection and chemical profiling of medicine counterfeits by Raman spectroscopy and chemometrics," Analytica Chimica Acta, vol. 705, no. 1-2, pp. 334-341, 2011.

[9] K. Kwok and L. S. Taylor, "Analysis of the packaging enclosing a counterfeit pharmaceutical tablet using Raman microscopy and two-dimensional correlation spectroscopy," Vibrational Spectroscopy, vol. 61, pp. 176-182, 2012.

[10] J. K. Mbinze, P.-Y. Sacré, A. Yemoa et al., "Development, validation and comparison of NIR and Raman methods for the identification and assay of poor-quality oral quinine drops," Journal of Pharmaceutical and Biomedical Analysis, vol. 111, pp. 21-27, 2015.

[11] S. Neuberger and C. Neusüss, "Determination of counterfeit medicines by Raman spectroscopy: systematic study based on a large set of model tablets," Journal of Pharmaceutical and Biomedical Analysis, vol. 112, pp. 70-78, 2015.

[12] J. Peters, A. Luczak, V. Ganesh, E. Park, and R. Kalyanaraman, "Raman spectral fingerprinting for biologics counterfeit drug detection," American Pharmaceutical Review, vol. 19, no. 2, 2016.

[13] P. De Peinder, M. J. Vredenbregt, T. Visser, and D. De Kaste, "Detection of Lipitor ${ }^{\circledR}$ counterfeits: a comparison of NIR and Raman spectroscopy in combination with chemometrics," Journal of Pharmaceutical and Biomedical Analysis, vol. 47, no. 4-5, pp. 688-694, 2008.

[14] F. E. Dowell, E. B. Maghirang, F. M. Fernandez, P. N. Newton, and M. D. Green, "Detecting counterfeit antimalarial tablets by near-infrared spectroscopy," Journal of Pharmaceutical and Biomedical Analysis, vol. 48, no. 3, pp. 1011-1014, 2008.

[15] J. Dubois, J. C. Wolff, J. K. Warrack, J. Schoppelrei, and E. N. Lewis, "NIR chemical imaging for counterfeit pharmaceutical products analysis," Spectroscopy, vol. 22, pp. 36-41, 2007, http://www.iesmat.com/iesmat/upload/file/Malvern/Product os-MAL/NIR-NIR\%20Chemical\%20Imaging\%20for\%20Cou nterfeit\%20Pharmaceutical\%20Products\%20Analysis.pdf.

[16] R. da Silva Fernandes, F. S. L. da Costa, P. Valderrama, P. H. Março, and K. M. G. de Lima, "Non-destructive detection of adulterated tablets of glibenclamide using NIR and solidphase fluorescence spectroscopy and chemometric methods," Journal of Pharmaceutical and Biomedical Analysis, vol. 66, pp. 85-90, 2012.

[17] M. B. Lopes and J. C. Wolff, "Investigation into classification/ sourcing of suspect counterfeit Heptodin ${ }^{\mathrm{TM}}$ tablets by near infrared chemical imaging," Analytica Chimica Acta, vol. 633, no. 1, pp. 149-155, 2009.

[18] S. H. F. Scafi and C. Pasquini, "Identification of counterfeit drugs using near infrared spectroscopy," The Analyst, vol. 126, no. 12, pp. 2218-2224, 2001.

[19] K. Dégardin, A. Guillemain, N. Viegas Guerreiro, and Y. Roggo, "Near infrared spectroscopy for counterfeit detection using a large database of pharmaceutical tablets," Journal of Pharmaceutical and Biomedical Analysis, vol. 128, pp. 89-97, 2016.

[20] J. R. Lucio-Gutierrez, J. Coello, and S. Maspoch, "Expeditious identification and semi-quantification of Panax ginseng using near infrared spectral fingerprints and multivariate analysis," Analytical Methods, vol. 5, no. 4, pp. 857-865, 2013.

[21] E. Deconinck, P. Y. Sacré, D. Coomans, and J. De Beer, "Classification trees based on infrared spectroscopic data to discriminate between genuine and counterfeit medicines," Journal of Pharmaceutical and Biomedical Analysis, vol. 57, pp. 68-75, 2011.

[22] C. Ricci, C. Eliasson, N. Macleod, P. Newton, P. Matousek, and S. Kazarian, "Characterization of genuine and fake artesunate anti-malarial tablets using Fourier transform infrared imaging and spatially offset Raman spectroscopy through blister packs," Analytical and Bioanalytical Chemistry, vol. 389, no. 5, pp. 1525-1532, 2007.

[23] K. Dégardin and Y. Roggo, "Counterfeit analysis strategy illustrated by a case study," Drug Testing and Analysis, vol. 8, no. 3-4, pp. 388-397, 2015.

[24] H. Ayvaz and L. E. Rodriguez-Saona, "Application of handheld and portable spectrometers for screening acrylamide content in commercial potato chips," Food Chemistry, vol. 174, pp. 154-162, 2014.

[25] A. Keil, N. Talaty, C. Janflet et al., "Ambient mass spectrometry with a handheld mass spectrometer at high pressure," Analytical Chemistry, vol. 79, no. 20, pp. 7734-7739, 2007.

[26] P. Leary, G. S. Dobson, and J. A. Reffner, "Development and applications of portable gas chromatography-mass spectrometry for emergency responders, the military, and law-enforcement organizations," Applied Spectroscopy, vol. 70, no. 5, pp. 888-896, 2016.

[27] J. D. Dunn, C. M. Gryniewicz-Ruzicka, J. F. Kauffman, B. J. Westenberger, and L. F. Buhse, "Using a portable ion mobility spectrometer to screen dietary supplements for sibutramine," Journal of Pharmaceutical and Biomedical Analysis, vol. 54, no. 3, pp. 469-474, 2010.

[28] C. R. Appoloni and F. L. Melquiades, "Portable XRF and principal component analysis for bill characterisation in forensic science," Applied Radiation and Isotopes, vol. 85, pp. 92-95, 2014.

[29] D. Lauwers, A. Candeias, A. Coccato, J. Mirao, L. Moens, and P. Vandenabeele, "Evaluation of portable Raman spectroscopy and handheld X-ray fluorescence analysis (hXRF) for the direct analysis of glyptics," Spectrochimica Acta Part A: Molecular and Biomolecular Spectroscopy, vol. 157, pp. 146-152, 2015.

[30] M. D. Hargreaves, K. Page, T. Munshi, R. Tomsett, G. Lynch, and H. G. M. Edwards, "Analysis of seized drugs using portable Raman spectroscopy in an airport environment - a proof of principle study," Journal of Raman Spectroscopy, vol. 39, no. 7, pp. 873-880, 2008.

[31] E. L. Izake, "Forensic and homeland security applications of modern portable Raman spectroscopy," Forensic Science International, vol. 202, no. 1-3, pp. 1-8, 2010.

[32] J. Zheng, S. Pang, T. P. Labuza, and L. He, "Evaluation of surface-enhanced Raman scattering detection using a handheld and a bench-top Raman spectrometer: a comparative study," Talanta, vol. 129, pp. 79-85, 2014.

[33] J. Jehlicka, P. Vítek, H. G. M. Edwards, M. Heagraves, and T. Capoun, "Application of portable Raman instruments for fast and non-destructive detection of minerals on outcrops," Spectrochimica Acta Part A: Molecular and Biomolecular Spectroscopy, vol. 73, no. 3, pp. 410-419, 2009.

[34] S. Assi, "Investigating the quality of medicines using handheld Raman spectroscopy," European Pharmaceutical Review, vol. 19, no. 5, pp. 56-60, 2014.

[35] A. J. O'Neil, R. D. Jee, G. Lee, A. Charvill, and A. C. Moffat, "Use of a portable near infrared spectrometer for the 
authentication of tablets and the detection of counterfeit versions," Journal of Near Infrared Spectroscopy, vol. 16, no. 3, pp. 327-333, 2008.

[36] J. E. Polli, S. W. Hoag, and S. Flank, "Comparison of authentic and suspect pharmaceuticals," Pharmaceutical Technology, vol. 33, no. 8, pp. 46-52, 2009.

[37] M. Alcalà, M. Blanco, D. Moyano et al., "Qualitative and quantitative pharmaceutical analysis with a novel hand-held miniature near infrared spectrometer," Journal of Near Infrared Spectroscopy, vol. 21, no. 6, pp. 445-457, 2013.

[38] K. Dégardin, Y. Roggo, and P. Margot, "Evaluation de Spectromètres Portables Raman, Infrarouge et Proche Infrarouge pour la Détection de Contrefaçons de Médicaments," Spectra Analyse, vol. 276, pp. 46-52, 2010.

[39] S. Assi, R. A. Watt, and A. C. Moffat, "Identification of counterfeit medicines from the internet and the world market using near-infrared spectroscopy," Analytical Methods, vol. 3, no. 10, pp. 2231-2236, 2011.

[40] A. Luczak and R. Kalyanaraman, "Portable and benchtop Raman technologies for product authentication and counterfeit detection," American Pharmaceutical Review, pp. 1-9, 2014.

[41] R. Bate and K. Hess, "Anti-malarial drug quality in Lagos and Accra - a comparison of various quality," Malarial Journal, vol. 9, no. 1, p. 157, 2010.

[42] R. Bate, R. Tren, K. Hess, L. Mooney, and K. Porter, "Pilot study comparing technologies to test for substandard drugs in field settings," African Journal of Pharmacy and Pharmacology, vol. 3, no. 4, pp. 165-170, 2009.

[43] D. E. Bugay and R. C. Brush, "Chemical identity testing by remote-based dispersive raman spectroscopy," Applied Spectroscopy, vol. 64, no. 5, pp. 467-475, 2010.

[44] M. Hajjou, Y. Qin, S. Bradby, D. Bempong, and P. Lukulay, "Assessment of the performance of a handheld Raman device for potential use as a screening tool in evaluating medicines quality," Journal of Pharmaceutical and Biomedical Analysis, vol. 74, pp. 47-55, 2012.

[45] R. Kalyanaraman, M. Ribick, and G. Dobler, "Portable Raman spectroscopy for pharmaceutical counterfeit detection," European Pharmaceutical Review, vol. 17, no. 5, pp. 35-39, 2012.

[46] C. Ricci, L. Nyadong, F. Yang et al., "Assessment of hand-held Raman instrumentation for in situ screening for potentially counterfeit artesunate antimalarial tablets by FT-Raman spectroscopy and direct ionization mass spectrometry," Analytica Chimica Acta, vol. 623, no. 2, pp. 178-186, 2008.

[47] J. Spink, D. C. Moyer, and M. R. Rip, "Addressing the risk of product fraud: a case study of the Nigerian combating counterfeiting and sub-standard medicines initiatives," Journal of Forensic Science and Criminology, vol. 4, no. 2, pp. 1-13, 2016.

[48] Y. Roggo, K. Dégardin, and P. Margot, "Identification of pharmaceutical tablets by Raman spectroscopy and chemometrics," Talanta, vol. 81, no. 3, pp. 988-995, 2010. 

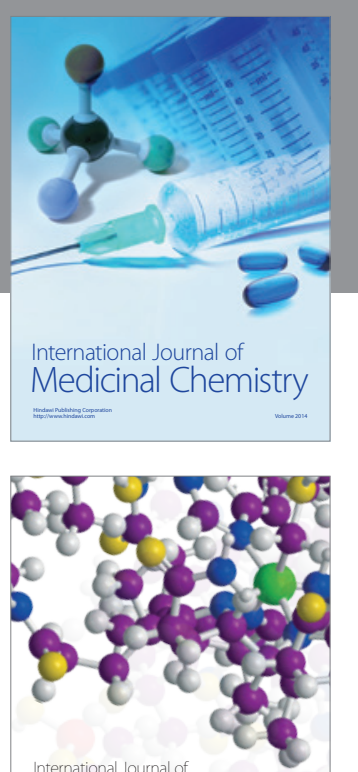

Carbohydrate Chemistry

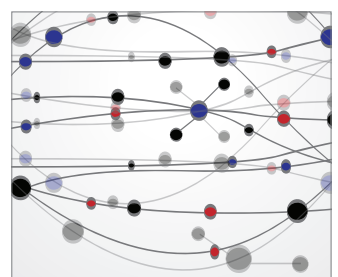

The Scientific World Journal
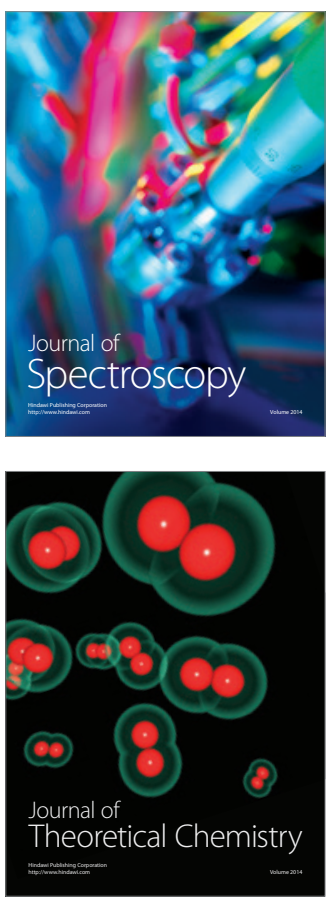
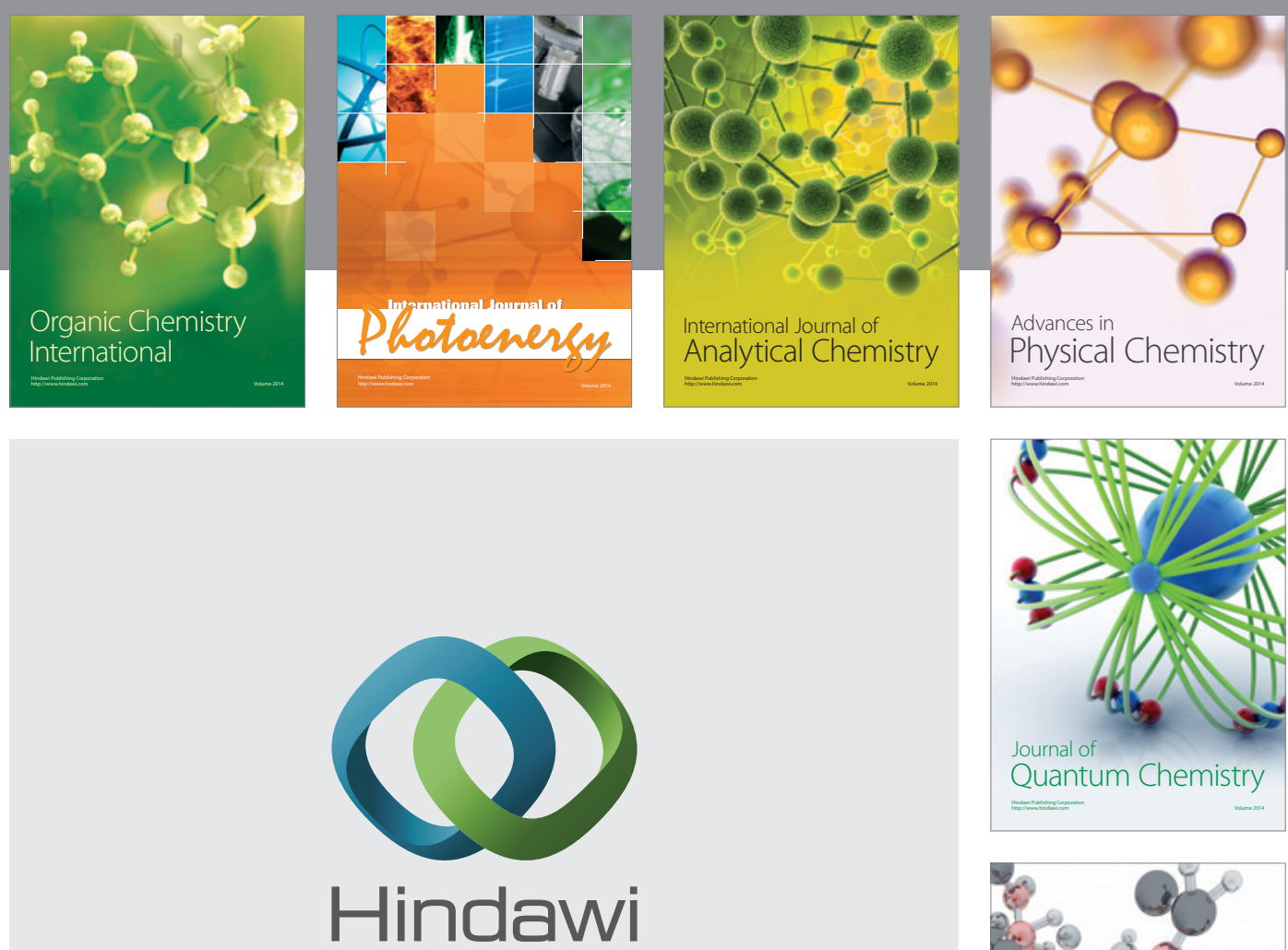

Submit your manuscripts at

https://www.hindawi.com

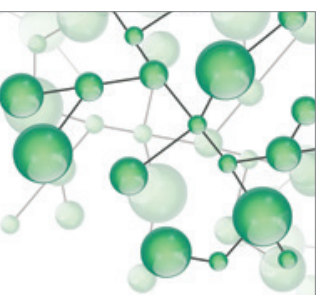

International Journal of

Inorganic Chemistry
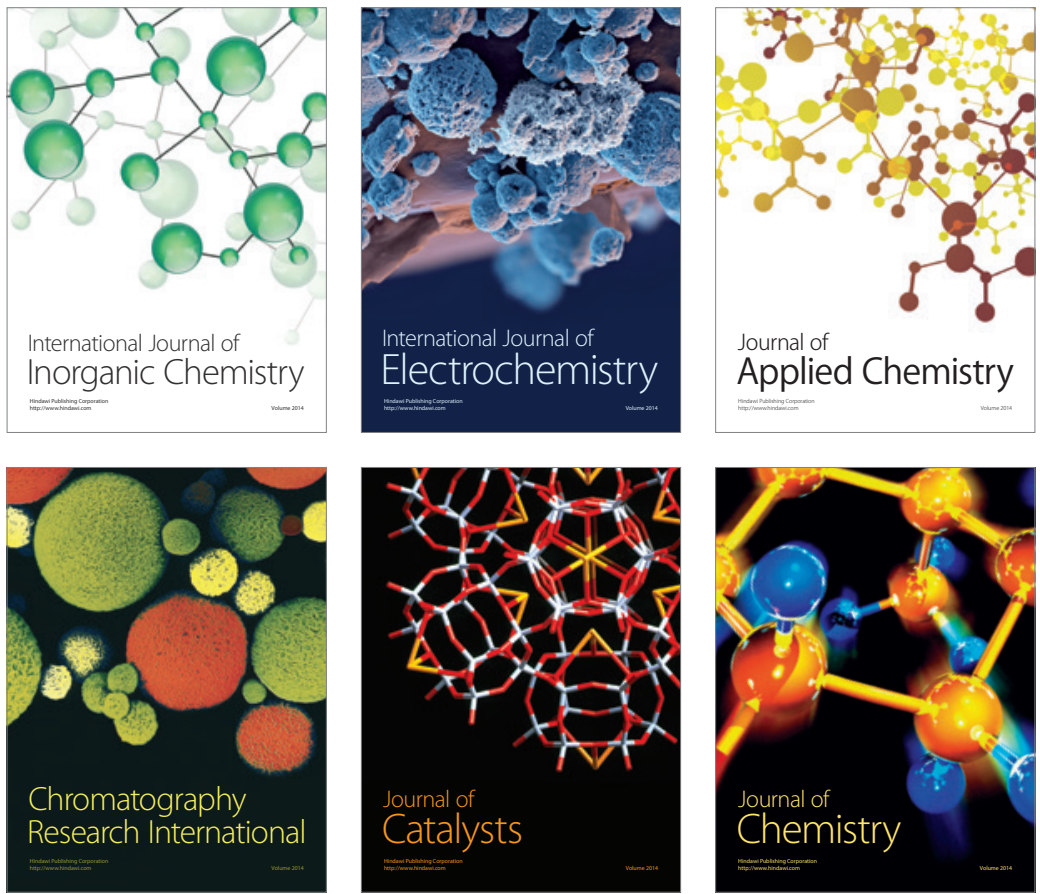

Journal of

Applied Chemistry
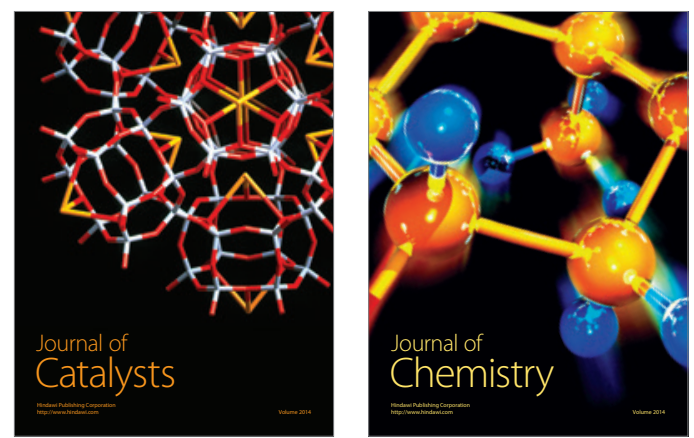
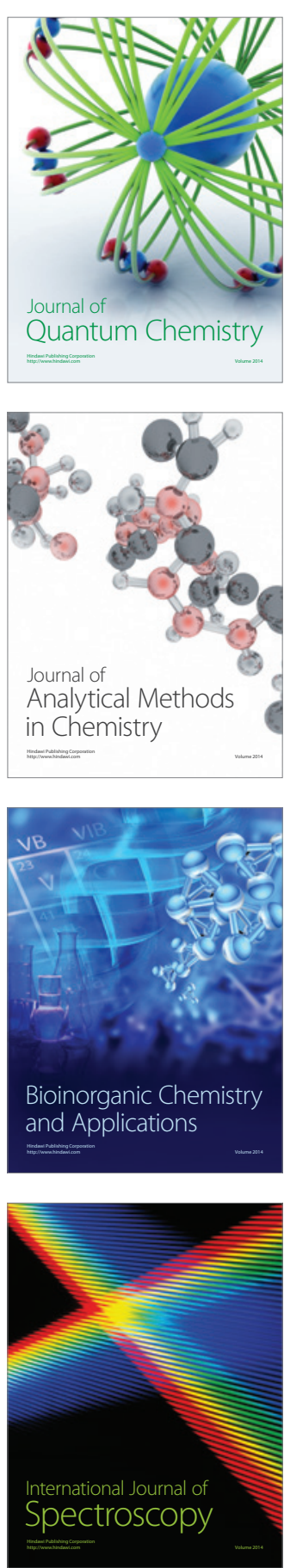